\title{
Model Predictive Current Control for Three-Phase Four-bridge Grid-Connected Inverters
}

\author{
Wenchao Xie, Yongqiang Zhu, Lihu Jia, Ruihua Xia \\ State Key Laboratory of Alternate Electrical Power System with Renewable Energy Sources, North \\ China Electric Power University, Beijing, China,102206
}

\begin{abstract}
Keywords: three-phase four-bridge grid-connected inverters, model predictive control, multi-step, value function.

Abstract. In the traditional three-phase four-bridge inverter control strategies, such as SAPWM, 3-D SVM, the control system of them are quiet complex, difficult to achieve engineering application, and the stability is poor. Therefore, in this paper, based on the combination of the model predictive current control strategy and three-phase four-bridge grid inverter mathematical model, a kind of easy to be realized multi-step three-phase four-bridge grid inverter control method has been proposed. This control strategy has abandoned a large number of nonlinear control links and pulse width modulation (PWM) modulator in the traditional control method, and established the discrete model of the inverter. Based on the prediction model and all possible switch states during the next period, make an online evaluation of the inverter output current, and then choose the switch state which makes the minimum value function to be applied in the next sampling interval. At last, simulation has been carried out on the PSCAD/EMTDC platform, the results verify that the proposed strategy is correct and effective, it can make the output current follow the change of the reference quickly, and it is not affected by the AC sides. Compared with the traditional method, this method has good static and dynamic characteristic and robustness, and the control method is simple and easy to be implement digital.
\end{abstract}

\section{Introduction}

In low voltage distribution network, the transmission line often adopts three-phase four-wire model, which brings power quality issues like harmonic and voltage. Besides, the three-phase imbalance load makes the neutral current overlarge and the change of the parameters of the grid is irregular. In order to solve the above problems, a topology structure that can be interconnected directly with three-phase four-wire system to realize the changes of the parameters of the grid, and can regulate and control the neutral current, is needed designing ${ }^{[1]}$. Four-bridge structure can provide zero-sequence component for three-phase imbalance load or nonlinear load. Experts have done a lot of research on the control technology of three-phase four-bridge inverters.

According to the diversity of power supply of the load in aircraft electric power source system, as well as the characteristic that the load needs mid-frequency current, Reference [2] constructs a function that injects 3-harmonic into the sinusoidal modulation wave to implement the circuit, which makes it more convenient to adopt SAPWM control in three-phase four-bridge inverter that has intermediate frequency output. The control effect is comparatively ideal.

Reference [3] applies SVM in four-bridge inverter and presents a two-dimension SVM control scheme of four-bridge inverter. Based on the principle that the average values of the output neutral-point voltages of four-bridge inverter and three-bridge inverter are equal in a switching period, the continuity signal of the fourth bridge is obtained.

Reference [4] has analyzed the voltage balance problem of the fourth bridge of three-phase four-bridge inverter, find out two factors affecting neutral voltage: switching frequency and the ratio of neutral line inductance and phase inductance. According to these two factors, three kinds of solutions was proposed to solve the fourth bridge voltage imbalance.

To sum up, most of those traditional four-leg control technologies adopts PID controller to decrease the steady state error and uses modulator to generate switching signals ${ }^{[5-10]}$. PI controller will bring many harmonics, and will also cause problems of dead band time and control delay. 
This article applys multi-step prediction method to three-phase four-bridge inverter control, on the other side, it analysis the multi-step predictive control briefly, And select the squared sum of prediction model inverter output curren and the reference current difference as optimization objective value function. Finally, by a large number of simulation experiments shows that MPC control algorithm can reduce output current distortion, improve power quality comared with traditional methods $^{[11-18]}$.

\section{Mathematical model}

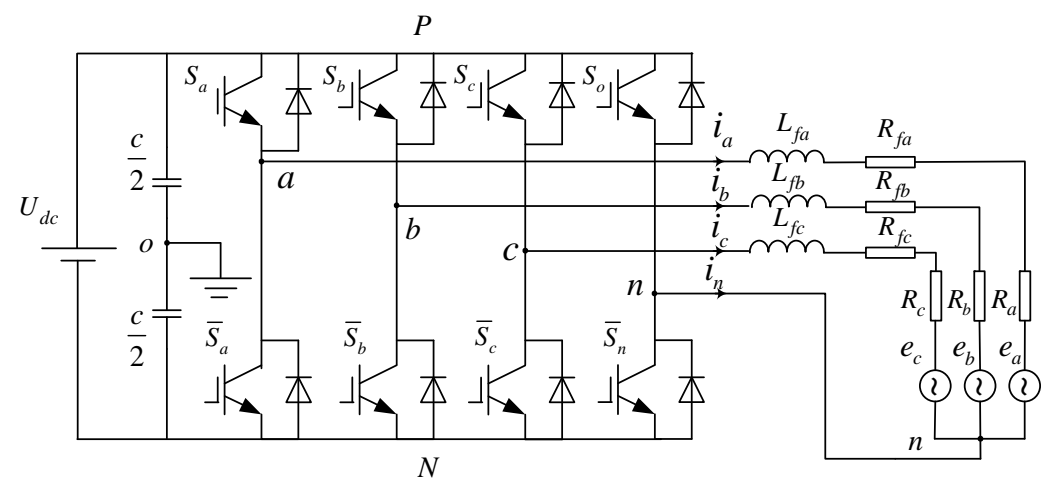

Figure 1. Structure of three-phase four-bridge inverter

The structure of three-phase four-bridge inverter is shown in Fig. 1. The output side connected to the grid through RL filter. $R_{\mathrm{f}}$ is the equivalent resistance of the filter, $\mathrm{L}_{\mathrm{f}}$ is the inductance value of the filter and $R$ is the equivalent resistance of the line; $i_{\mathrm{a}}, i_{\mathrm{b}}, i_{\mathrm{c}}$ are output current of inverter; $e_{\mathrm{a}}, e_{\mathrm{b}}, e_{\mathrm{c}}$ are voltage of interconnection point; neutral wire is connected to the fourth bridge of the inverter; split capacitance is used in DC side, $O$ is grounded.

Each bridge has two different switch states: upper bridge on, lower bridge off or lower bridge on, upper bridge off, so there are $2^{4}=16$ switch states, using switch function $S_{\mathrm{i}}$ describe ${ }^{[14]}$ :

$$
S_{i}=\left\{\begin{array}{l}
1 \text {, upper bridge on } \\
0 \text {, lower bridge on }
\end{array}(i=a 、 b 、 c 、 n)\right.
$$

The relationship between output voltage of inverter and switch function can describe as follows:

$$
v_{j n}=\left(S_{j}-S_{n}\right) v_{d c}, j=a, b, c
$$

According to the Kirchhoff, output voltage and output current of the inverter can be written as functions like this ${ }^{[14]}$ :

$$
\left\{\begin{array}{l}
v_{j n}=\left(R_{f j}+R_{j}\right) i_{j}+L_{f j} \frac{d i_{j}}{d t}+e_{j}, j=a, b, c \\
i_{a}+i_{b}+i_{c}=-i_{n}
\end{array}\right.
$$

The first equation of Eq. 2 can be written as follows, which is the mathematical model of three-phase four-bridge inverter in continuous state ${ }^{[14]}$.

$$
\frac{d i_{j}}{d t}=\frac{1}{L_{f j}}\left[\left(v_{j n}-e_{j}\right)-\left(R_{f j}+R_{j}\right) \cdot i_{j}\right], j=a, b, c
$$

\section{The principle of multi-step model predictive current control}

Model predictive current control technology is based on the precise mathematical model of the system, it can predict the current instruction during the next switch period according to the system information present and past, choose the optimal switch combination through appropriate value 
function to follow current instruction precisely. Scheme of the predictive current control as shown in Fig. 2. ${ }^{[15]}$

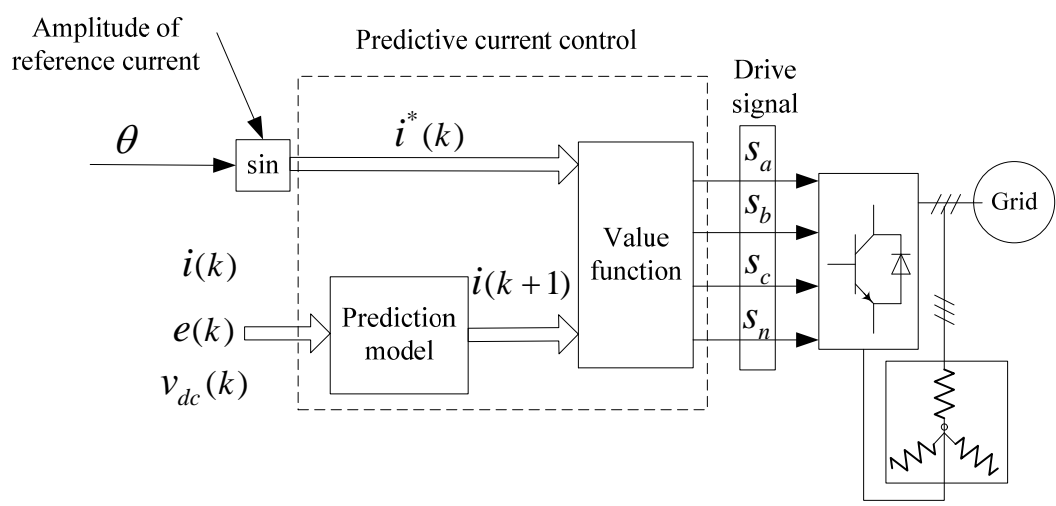

Figure 2. Scheme of the predictive current control

From Fig. 2, we can see that the predictive current control consist of five parts:

1) Measure module, it role is to measure the grid voltage, output current of inverter, voltage of DC and then send these message to the prediction model of system.

2) Prediction module, control system is based on optimal algorithm, it can be easily achieved in hardware. After established the continous model of system, it need to be discretized.

With equation $\frac{d i}{d t}=\frac{i(k+1)-i(k)}{T s}$, we can have the recursive relation:

$$
i(k+1)=C v \cdot[v(k)-e(k)]-C i \cdot i(k)
$$

In Eq. 4, $C v=\frac{T s}{L f}, C_{i}=1-\frac{T s(R f+R)}{L f}$.

With information of moment $k$ and Eq. 4, we can calculate the predictive value of current in moment $k+1$. In reference [15], traditional one-step method only considerate the optimal of switch function in one period, two or more period it don't take into consideration, so it will neglect the optimal of other combination of switch function, and it will cause the control system into oscillation and divergent. To solve this problem, this paper using two-step prediction algorithm.

3) Calculation module of current instruction, supply power to the load, we can calculate the load to get instruction; grid-connected system, we can calculate current instruction through the power grid supplied.

4) Value function, establish the value function with current instruction and current value in moment $\mathrm{k}+1$, described as follows:

$$
c=\left[i_{a}^{*}-i_{a(k+1)}\right]^{2}+\left[i_{b}^{*}-i_{b(k+1)}\right]^{2}+\left[i_{c}^{*}-i_{c(k+1)}\right]^{2}
$$

5) Signal drive module, in order to control the output current of inverter, choose the optimal switch state during the next switch period according to the value function.

Control process of two-step predictive control algorithm shown in Fig. 3, in actual engineering, the computation time of digital signal controller can't be ignored, but it can compensate control delay by construct the value function through predictive value $i(k+2)$ of the next sampling period. Through the value function, select two switch combination which respectively make the value function minimum and next-minimum, and then, with value $i(k+1)$, calculate $i 1(k+2), i 2(k+2)$ of $i(k+2)$, calculate $i(k+3)$ with $i 1(k+2), i 2(k+2)$ and 16 switch function, construct value funcion with i(k+3), select switch function that make the value function minimum role in moment $k+1$. Two-step method can effectively prevent the control system oscillation and divergence in one-step method ${ }^{[18]}$. 


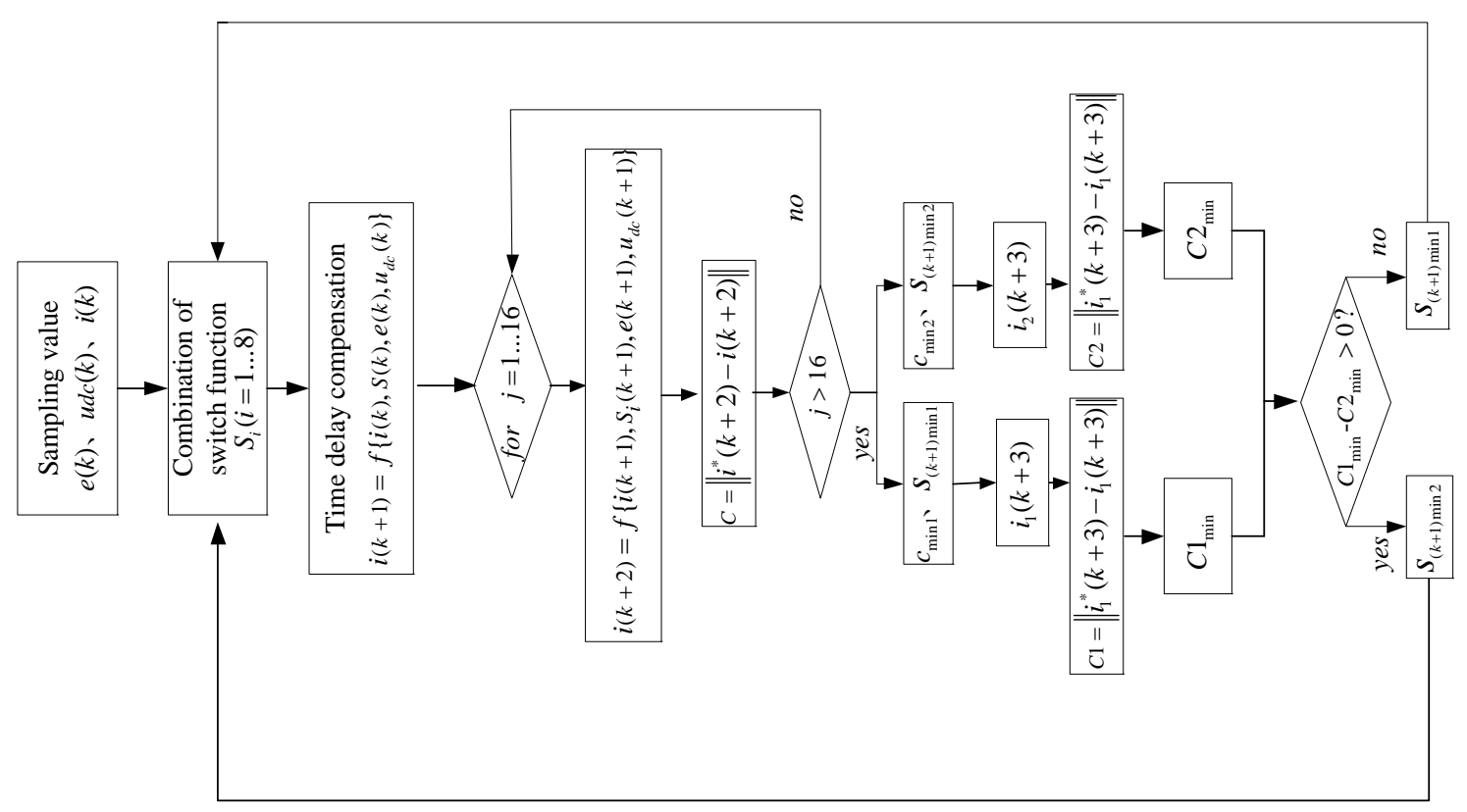

Figure 3. Multi-step control flow of model predictive current control

\section{Simulation results}

For verifying its performance, PSCAD/EMTDC simulation was executed with the proposed model predictive current control. Simulation is mainly for the following situation: (1) current instruction is changing when power grid voltage is three-phase symmetrical; (2) short-circuit fault happened in grid side; (3) precision of model is affected by circuit parameters change.

(1) Current instruction is changing when power grid voltage is three-phase symmetrical Power grid voltage and frequency is set to $E_{\mathrm{a}}=E_{\mathrm{b}}=E_{\mathrm{c}}=220 \mathrm{~V}, 50 \mathrm{~Hz}$, respectively.

a. Reference value of current is $I_{a}^{*}=I_{b}^{*}=I_{c}^{*}=12 \mathrm{~A}$, sampling time is $20 \mu \mathrm{s}$, simulation waveform shown in Fig. 4.

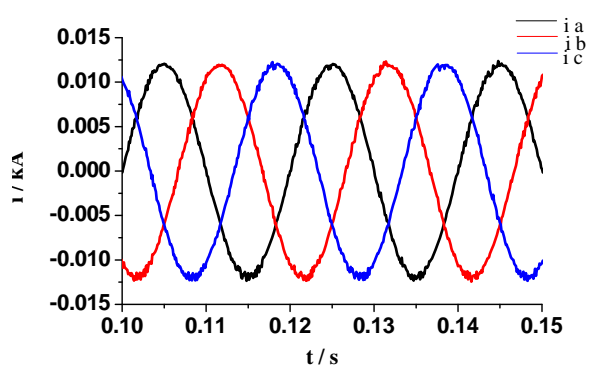

(a) Three phase current waveform

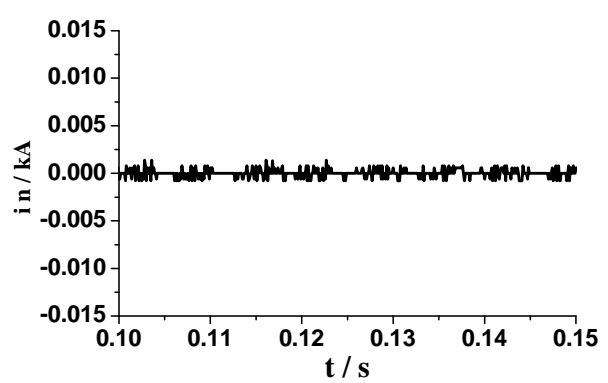

(b) The neutral wire current waveform

Figure 4. The simulation waveform of the current reference three-phase symmetrical

From Fig. 4, output current of inverter can follow the reference current very well, current of neutral wire almost zero when three phase voltage balance. The rate of three phase current distortion is $0.697,0.711,0.719$, no more than $0.8 \%$, meet the requirements of power quality

b. Reference value of current is $I_{a}^{*}=12 \mathrm{~A}, I_{b}^{*}=10 \mathrm{~A}, I_{c}^{*}=8 \mathrm{~A}$, sampling time is $20 \mu \mathrm{s}$, simulation waveform shown in Fig. 5. 


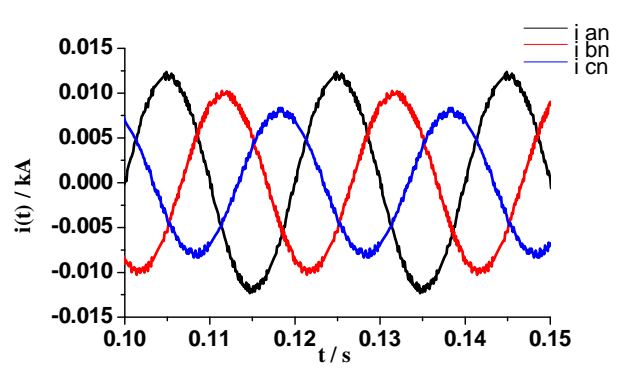

(a) Three phase current waveform

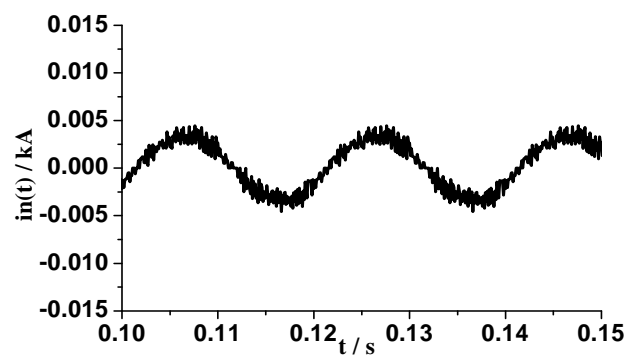

(b) The neutral wire current waveform

Figure 5. The simulation waveform when current reference amplitude asymmetric

The amplitude of reference current in Fig. 5 (a) are not equal, output current of inverter can follow the current instruction very well through the control system, the current of neutral wire is not zero because imbalance of three phase current. The rate of three phase current distortion is $0.632,0.852$, 0.964 , they are not equal and will increase with the reference value decrease. It is said that this control system can control each phase current independently.

c. Reference value of current become $I_{a}^{*}=I_{b}^{*}=I_{c}^{*}=12 \mathrm{~A}$ from zero when time is $0.12 \mathrm{~s}$, sampling time is $20 \mu s$, simulation waveform shown in Fig. 6.

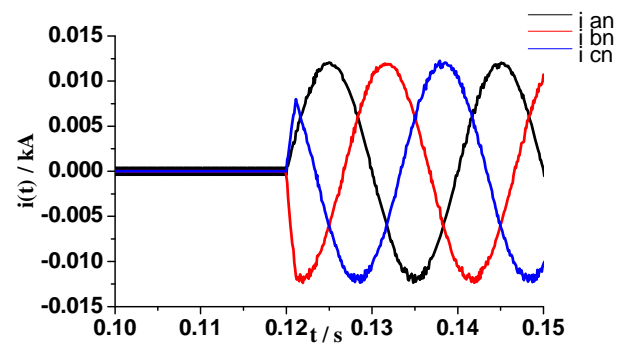

(a) Three phase current waveform

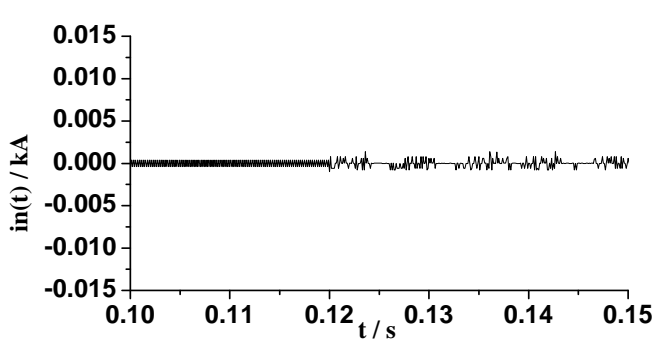

(b) The neutral wire current waveform

Figure 6. The simulation waveform of reference current mutation

From Fig. 6 we can see that output current of inverter can follow reference value rapidly when mutation of reference current has happened, this is said that the system has great dynamic performance.

\section{(2) Short-circuit fault happened in grid side}

Grid voltage $E_{\mathrm{a}}=E_{\mathrm{b}}=E_{\mathrm{c}}=220 \mathrm{~V}$, phase A grounded fault happened in $0.1 \mathrm{~s}$, grounding inductance $L=1 \mathrm{mH}$, grounding resistance $R=0.01 \Omega$, other parameters are same as simulation (1).

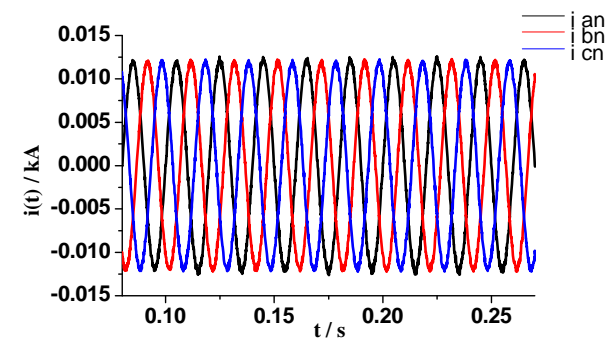

(a) Three phase current waveform

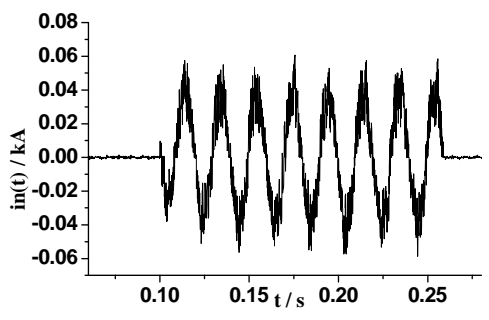

(b) The neutral wire current waveform

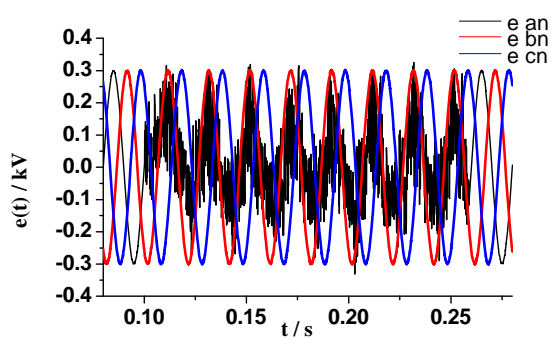

(c) Phase voltage of inverter output

Figure 7. The simulation waveform when single-phase grounded fault occurs

Distortion rate THD before and after the fault shown in table 1 and table 2. Distortion rate of phase $\mathrm{A}, \mathrm{B}, \mathrm{C}$ is $0.968,0.891,0.804$ during the fault. After the fault recovery, distortion rate become 0.741 , 0.826, 0.804, and we can see that distortion rate of phase A changes obviously. Based on the current prediction control strategy, output current can varied by follow the reference value, and affected by the outside conditions very small. 


\begin{tabular}{|c|c|c|c|}
\hline Line current & THD & $\begin{array}{c}\text { Phase } \\
\text { voltage }\end{array}$ & THD \\
\hline$I_{\mathrm{a}}$ & 0.967799 & $E_{\mathrm{a}}$ & 108.905 \\
\hline$I_{\mathrm{b}}$ & 0.892099 & $E_{\mathrm{b}}$ & 0.355587 \\
\hline$I_{\mathrm{c}}$ & 0.868233 & $E_{\mathrm{c}}$ & 0.346013 \\
\hline
\end{tabular}

Table 2. Inverter output current, voltage distortion rate (\%)

\begin{tabular}{|c|c|c|c|}
\hline Line current & THD & Phase voltage & THD \\
\hline$I_{\mathrm{a}}$ & 0.741122 & $E_{\mathrm{a}}$ & 0.294929 \\
\hline$I_{\mathrm{b}}$ & 0.825598 & $E_{\mathrm{b}}$ & 0.328696 \\
\hline$I_{\mathrm{c}}$ & 0.803657 & $E_{\mathrm{c}}$ & 0.319828 \\
\hline
\end{tabular}

From Fig. 7, output current and output voltage keep balance when grid voltage symmetrical, and able to changes by following the reference instructions, and the steady-state error is very small; When grounded fault happened, Although the voltage waveform of fault phase suffered serious distortion, the normal phase voltage are same as the running state when three phase symmetrical, and output current of inverter has no changes during the fault.

\section{(3) Problem about model precision is affected by circuit parameters change}

Two situation are take into consideration: (1) parameters of transmission line changed, but parameters of controller are still the same; (2) parameters of transmission line changed, and parameters of controller changes corresponding. With three phase current distortion rate as an index to evaluate the control precision of the model. Results are shown in table 3.

Table 3. Inverter output current, voltage distortion rate (\%) when the circuit parameters change

\begin{tabular}{|c|c|c|c|c|}
\hline \multirow{2}{*}{$\begin{array}{c}\text { Inductance value of } \\
\text { controller/(mH) }\end{array}$} & $\begin{array}{c}\text { Actual inductance } \\
\text { value } \\
/(\mathrm{mH})\end{array}$ & \multicolumn{3}{|c|}{ Distortion rate of three phase current (\%) } \\
\cline { 2 - 5 } & 20 & $I_{\mathrm{a}}$ & $I_{\mathrm{b}}$ & $I_{\mathrm{c}}$ \\
\hline 40 & 20 & 1.37822 & 1.37624 & 1.47875 \\
\hline 20 & 40 & 0.660508 & 0.679757 & 0.698648 \\
\hline 40 & 60 & 0.557433 & 0.519364 & 0.51493 \\
\hline 40 & 60 & 0.561774 & 0.543511 & 0.540153 \\
\hline 60 & 80 & 0.535863 & 0.557588 & 0.607135 \\
\hline 40 & 80 & 0.381343 & 0.375988 & 0.389164 \\
\hline 80 & 120 & 0.647114 & 0.632662 & 0.641792 \\
\hline 40 & 120 & 0.381343 & 0.375988 & 0.389164 \\
\hline 120 & & & & \\
\hline
\end{tabular}

With data of Tab. 3, when parameters of transmission line changed, no matter corresponding parameters in controller changed or not, the influence of output current is very small, so we can conclude that the stability of converter control technology based on the model current control technology is good.

\section{Summary}

This paper presents a model predictive current control strategy, and has been verified by plenty of simulation that the dynamic characteristics and robustness is better than traditional control strategy. Using inverter discretization model characteristics, and according to its limited switch state and dc voltage to predict system behavior of the next moment, with the help of value function to select the optimal switch state, simulation results has already verified that output current of inverter can follow reference current very well, and improve the quality of Sinusoidal current. Harmonic content and current distortion rate can be controlled to meet the requirements of power quality, and not affected by load and grid voltage changes. 


\section{References}

[1] Hongbin Chen. Four-leg Power Converter in Power Conversion System (PCS) of Energy Storage and Its Control Strategies. Hefei University Technology, 2013.

[2] Zheng Wei, Kai Chen, Yihan Chen, Chensong Li, Chunying Gong. A Novel Method for SAPWM Control of Three-Phase Four-Leg Inverter [J] . Transactions of China Electrotechnical Society, 2013, 07:199-204.

[3] Hong Yang. The Control and Realization of Four-Leg Three-phase Inverter [D]. Nanjing University of Aeronautics and astronautics, 2005 .

[4] Zeng Liu, Jinjun Liu, Jin Li. Modeling, Analysis, and Mitigation of Load NeutralPoint Voltage for Three-Phase Four-Leg Inverter [J]. IEEE Transactions on Industrial Electronics, 2013, 60(5): 2010-2020.

[5] Yongchao Liu, Zhenyu Yang, Jun Yao, Jian Feng. Simulative research on three-phase four-leg dynamic var compensator $[\mathrm{J}]$. Electric Power Automation Equipment, 2006, $11: 24-27$.

[6] Rui Wu, Shaojun Xie. Research on the Four-Leg Voltage Source Inverters Based on Space Vector Modulation in abc Coordinates [J]. Transactions of China Electrotechnical Society, 2005, 12:47-52.

[7] Xiuchong Liu, Huaguang Zhang, Hongzhi Chen. Control Strategy of Fourth Leg in Four-leg Inverter [J]. Proceedings of the CSEE, 2007, 33:87-92.

[8] Lanling Fei. The Control and Realization of Three-Phase Four-Leg Inverter under Unbalanced Loads [D]. Huazhong University of Science \& Technology, 2011.

[9] Fengbin Dong, Jinfeng Huang, Zhouxing FU. Analysis of mathematical model for three-phase four-leg inverters [J] . Electric Power Automation Equipment, 2011, 06:98-101.

[10]Ling Chen, Xing Zhang, Shuying Yang, Zhen Xie. Study on the three-phase four-leg inverter with unbalanced loads [J]. Journal of Hefei University of Technology, 2009, 04:486-490.

[11] Marco Rivera， Venkata Yaramasu ， Ana Llor, et al. Digital Predictive Current Control of a Three-Phase Four-Leg Inverter[J]. IEEE Transactions on Industrial Electronics, 2013, 60(11): 4903-4911.

[12]Kouro S , Cortes P, Vargas R, et al. Model predictive control—a simple and powerful method to control power converters[J]. IEEE Transactions on Industrial Electronics， 2009, 56(6): 1826-1838.

[13]Patricio C, Gabriel Otriz, Juan I, et al. Model Predictive Control of an Inverter With Output LC Filter for UPS Applications[J]. IEEE Transactions on Industrial Electronics, 2009, 56(6): 1875-1883.

[14]José Rodríguez, Jorge Pontt, César A. Silva, et al. Predictive Current Control of a Voltage Source Inverter[J]. IEEE Transactions on Industrial Electronics, 2007 , 54(1):495-5033. 
[15]Patricio Cortés, Marian P. Kazmierkowski Ralph M. Kennel, et al. Predictive Control in Power Electronics and Drives[J]. IEEE Transactions on Industrial Electronics, 2008, 55(12): 4312-4323.

[16] Ali M. Almaktoof, A. K. Raji, and M. T. E. Kahn. Modeling and Simulation of Three-Phase Voltage Source Inverter Using a Model Predictive Current Control[J]. International Journal of Innovation, Management and Techo -logy, 2014, 5(1):9-13.

[17] Venkata Yaramasu, Marco Rivera, Bin Wu, et al. Model Predictive Current Control of Two-LevelFour-Leg Inverters-Part I: Concept , Algorithm , and Simulation Analysis[J]. IEEE Transactions on Power Electronics， 2013， 60(11): 3459-3467.

[18]Kun Shen, Jing Zhang, Jian Wang. A Model Predictive Control Scheme of Multi-step Prediction Finite Control Set for Converters [J]. Proceedings of the CSEE, 2012，32:37-44. 